•编者按・

\title{
中国高等植物濒危状况评估
}

\author{
覃海宁 $1^{*}$ 赵莉娜1,2
}

1 (中国科学院植物研究所系统与进化植物学国家重点实验室, 北京 100093)

2 (中国科学院大学生命科学院, 北京 100049)

\section{Evaluating the threat status of higher plants in China}

\author{
Haining Qin ${ }^{1 *}$, Lina Zhao ${ }^{1,2}$ \\ 1 State Key Laboratory of Systematic and Evolutionary Botany, Institute of Botany, Chinese Academy of Sciences, Beijing \\ 100093 \\ 2 College of Life Sciences, University of Chinese Academy of Sciences, Beijing 100049
}

《中国高等植物红色名录》首次完成了中国 35,000 余种野生高等植物的濒危状况评估, 于 2013 年由环境保护部和中国科学院以 54 号公告形式联 合发布, 这是继南非之后, 全球生物多样性大国中 第二个完成境内全部高等植物红色名录评估的国 家。本期稿件是在2013年发布的名录基础上进行了 少量更新和调整, 由名录的 4 个评估小组首次详细 介绍了中国苔藓植物(何强和贾渝, 2017)、彍类植物 (董仕勇等, 2017)、裸子植物(杨永等, 2017)和被子植 物(覃海宁等, 2017b)红色名录的评估过程、发现和 科学意义, 并以开放获取期刊文献的方式发表了 《中国高等植物受威胁物种名录》(覃海宁等, 2017a), 供广大读者查阅检索。

与本专辑一同发表的还有“野生牡丹的生存 状况和保护”(洪德元等, 2017)和“中国生物多样性 保护的国家意志、科学决策和公众参与: 中国第 一份省域物种红色名录研究” (蒋志刚和马克平, 2017)两篇文章。前者积多年野外实地观察和研究 结果, 全面报道了我国野生牡丹资源的调查及研 究历史、分布状况和致危因素, 并提出保护措施; 后者则报道了“植物王国”云南省研制省级植物红 色名录的历程及意义。这些文章的结集发表, 让读 者多层次地了解我国植物红色名录及濒危物种研 究的最新进展及其对我国生物多样性保护的推动 作用。

\section{1 中国高等植物多样性受威胁及保护现状}

中国是全球生物多样性大国之一, 高等植物种 数约占全球种数的 $8-12 \%$ (Mittermeier et al, 1997; Zhang \& Gilbert, 2015)。中国也是北半球物种最丰 富的国家，与美国和欧洲有着相近的陆地面积，但 具有更为丰富的生物多样性。以维管植物(包括蒝类 和种子植物)为例, 中国拥有 31,000 多种, 而美国和 欧洲分别有 19,000种和11,500种(Raven, 2011), 比例 为 $3: 2: 1$; 而且, 维管植物中特有植物约占一半 (Huang et al, 2011; Wu et al, 2013a; 王利松等, 2015)。同时，药用、观赏、经济植物十分丰富，有 许多在农、林、牧、医和轻化工业上很有价值的植 物种质资源。

当前, 中国生物多样性仍然面临着巨大压力。 20 世纪的人口剧烈增长, 加上近二、三十年的高速 经济发展, 造成森林和其他自然生态系统的退化甚 至丧失, 其中的物种资源受到严重影响。此外, 人 为过度采挖、外来种入侵、自然灾害等也是造成物 种濒临灭绝的重要原因。即使是列入各类保护名录 的物种, 例如红豆杉(Taxus spp.)、兰花、苏铁(Cycas spp.)、肉苁蓉(Cistanche spp.) 和甘草(Glycyrrhiza uralensis)等也频频遭受盗采滥挖以及非法贸易等 威胁(檀丽萍和陈振峰, 2006; 张翔宇和王一涛, 2009; Lenzen et al, 2012; 王亚飞等, 2012; 屠鹏飞

基金项目: 环境保护部“生物多样性保护专项”——中国高等植物红色名录和国家标本资源共享平台一一植物子平台(2005DKA21401)

* 通讯作者 Author for correspondence. E-mail: hainingqin@ibcas.ac.cn 
等, 2015)。

物种濒危状况评估是实施生物多样性优先保 护的重要工具(Mace \& Lande, 1991; Vié et al, 2008), 对于制订物种保护管理政策和策略尤其重要。因为 多数情况下可用的保护信息资源很有限, 故采取的 保护策略往往就是直接保护面临最大灭绝风险的 小部分物种(de Grammont \& Cuarón, 2006; Mace et al，2008)。世界自然保护联盟(IUCN)濒危物种红色 名录(简称“IUCN红色名录”) 是评价和展示生物物 种濒危和灭绝风险的最好系统之一, 在世界各国中 得到最广泛的应用(de Grammont \& Cuarón, 2006; Miller et al, 2007; 蒋志刚, 2016)。《中国珍稀濒危保 护植物名录: 第一册》 (国家环境保护局和中国科学 院植物研究所, 1987) 首次采用当时的IUCN红色名 录濒危等级(Lucas \& Synge, 1978)中濒危、稀有、渐 危等等级标注了 388 种维管植物, 包括 13 种薑类植 物和 375 种种子植物的濒危状况; 随后, 国家环境 保护局(现为国家环境保护部)和中国科学院植物研 究所组织众多植物学专家基于该名录开展野外调 查, 并编写了 《中国植物红皮书: 稀有濒危植物(第 一册)》(傅立国和金鉴明，1991) 一书。这两本著作 的出版深受国内外读者特别是从事植物物种保护、 管理工作和广大科研工作者的好评。《中国物种红 色名录(第一卷): 红色名录》(汪松和解炎, 2004)采 用IUCN红色名录(3.1版) (IUCN，2001)选择评估了 全国4,409种种子植物的濒危状况, 其中 3,782种为 受威胁等级, 占评估总数的 $85.8 \%$ 。此外, 从类群角 度看，黄卫昌等(2015) 评估了中国虾脊兰属 (Calanthe)植物的濒危状况, 曹同等(2006)和 Cao等 (2006)提出了首批中国濒危苔藓植物红色名录(计 82种), 严岳鸿等(2013)报道了全国硕类植物的红色 名录等级。

上述各类中国植物红色名录的出版对我国植 物多样性保护及研究起到了重要作用, 但也存在明 显不足, 例如评估物种数量较少, 所用资料陈旧或 没有严格采用IUCN评估方法, 或未能充分吸收专 家参与等。为及时和全面反映本世纪初以来我国野 生植物物种资源消长状况并掌握整个中国植物区 系健康状况和受威胁程度, 以便为制订生物多样性 保护策略和国际履约提供科学依据, 环境保护部联 合中国科学院启动了“中国生物多样性红色名录: 高等植物卷”的编制工作(藏春金金等, 2016)。
本次评估研究是在国内红色名录及珍稀濒危 保护植物名录的基础上, 采用广泛收集文献标本资 料和专家调查相结合的方法, 全部评估了国产野生 高等植物共 35,000 余种的濒危状况, 编制了新的中 国高等植物红色名录, 以供构建全国生物物种多样 性指标系统参考。

\section{2 中国高等植物红色名录评估标准及实施 步骤}

IUCN濒危物种红色名录是基于物种过去、现 在和将来(预期)的威胁因子来评估物种的灭绝风险, 并把物种置于相应濒危等级的系统。其评估依据(威 胁因子)包括种群大小及变动趋势、成熟个体数量以 及种群分布面积等影响种群生存的各项因素。该系 统的特点在于减少主观判断, 力求明确并量化, 全 面考虑评估信息和评估过程的不确定性(Mace \& Lande, 1991; IUCN, 2012a)。其濒危等级包括灭绝 $(\mathrm{EX}) 、$ 野外灭绝 $(\mathrm{EW}) 、$ 极危 $(\mathrm{CR})$ 、濒危 $(\mathrm{EN})$ 、易危 $(\mathrm{VU}) 、$ 近危 $(\mathrm{NT}) 、$ 无危 $(\mathrm{LC})$ 和数据缺乏(DD) 等 8 个 等级。其中，极危、濒危和易危统称受威胁等级 (Threatened Category), 受威胁等级物种(简称受威 胁物种)是生物多样性优先保护的重点关注对象。当 评估不是在全球层面而是地区层面，例如在国家级 进行时, 增加地区灭绝(Regionally Extinct, RE)等级, 共9个等级(IUCN，2012b)。这也是此次中国高等植 物红色名录评估所使用的等级。

本次红色名录评估严格按照IUCN红色名录方 法和工作流程进行。评估标准主要依据IUCN红色 名录等级标准(IUCN，2012a)及其使用指南(IUCN Standards and Petitions Subcommittee, 2011)和地区 应用指南(IUCN, 2012b)等三个文件。在评估程序上 遵循IUCN推荐的模式, 即预评估(pre-assessment)、 评估(assessment)、审核(review)和一致性检查(consistency check)等四个环节, 并在实施过程中根据中 国植物成分和研究基础等实际情况, 对IUCN红色 名录标准指标及评估方法进行必要的细化和补充。 例如, 本次研究所采用的“建立权威名录”、“全面收 集素材”、“专业团队评估”和“广邀专家审核”等评估 程序“四部曲”就是我们所建立的。

此次中国高等植物红色名录研究前后历时数 年, 收集和参考了大量线上线下论文及标本信息, 包括数千篇(本)正式发表论文(论著)及研究生学位 
论文和数百万份数字标本, 邀请了来自 90 家科研院 所及大专院校的 300 位植物学专家及研究生参与名 录信息调查或评估结果审核工作(附录1)。可以说, 这是一次政府主导、科研机构承担、基于现有信息 数据资源、发动全国专家实施的对整个中国植物区 系濒危和健康状况的评估。

\section{3 中国高等植物红色名录评估的结果及意义}

综合本次各类群植物评估结果可以看出, 在野 生高等植物共计 35,784种评估物种中, 灭绝21种, 野外灭绝 9 种, 地区灭绝 10 种, 极危 614 种, 濒危 1,313种，易危1,952种，近危2,818种; 无危24,243种， 数据缺乏 4,804 种(表1)。其中的 40 个灭绝种都是被子 植物; 受威胁物种 $(\mathrm{CR} 、 \mathrm{EN} 、 \mathrm{VU})$ 共计 3,879 种, 受 威胁比例为 $10.84 \%$ 。另外, 近危种和数据缺乏种分 别占 $7.88 \%$ 和 $13.42 \%$, 前者如果近期内致危因子没 有解除甚至加强, 则可能升级成为受威胁等级; 后 者可能会随着分类学研究的加强和野外调查工作 的深入而被确定为受威胁等级。据此可以认为, 以 往推测中国高等植物受威胁比例为 $15-20 \%$ 是合理 的。(中国植物保护战略编撰委员会, 2008; 中国生 物多样性保护战略与行动计划编写组, 2011)。

由于不同高等植物类群间的生存环境、研究基 础和经济价值差别较大, 各类群物种受威胁的程度 也存在较大的差异。例如, 裸子植物受威胁程度最 高, 达到58.0\% (148/251), 苔藓植物受威胁程度最 低, 占5.80\% $(186 / 3,221)$ 。裸子植物中, 我国有分布 的 22 种苏铁科植物全部为受威胁物种, 受威胁比例 达 $100 \%$, 红豆杉科(16/23)和罗汉松科(11/14)濒危比
例分别为 $70.0 \%$ 和 $78.6 \%$ 。

根据本次评估收集到的数据, 我们对 3,879 种 受威胁物种的致危因子初步进行分析。结果表明, 造成我国植物濒危的因素包括: (1)生境退化和丧失; (2)人为过度利用; (3)物种自身因素, 包括分布面积 过小，极小种群以及繁育系统问题; (4)种间影响, 包括入侵种影响和病虫害侵扰; (5)环境污染; (6)自 然灾害和气候变化等六大类。这个结论与基于全球 濒危物种(Vié et al, 2009)及中国濒危动物(魏辅文等, 2014; 蒋志刚, 2016)的分析结果基本一致。有所不 同的是, 中国高等植物最主要和突出的致危因子是 生境退化和丧失, 尤其是近年来兴起的基本建设热 (包括城镇建设、路网建设等)、热带经济作物种植 热以及自然保护区和国家森林公园生态旅游热, 均 对野生植物的生存环境产生了巨大的压力。此外, 虽然人为过度采挖(药用植物和观赏植物等)仍然位 列植物致危因子的第二位，但近年来呈现相对减弱 的趋势, 这可能是得益于政府密集出台各种保护规 章措施和民众保护意识增强的结果。

红色名录是基于现有资料信息对物种的生存 前景和灭绝风险做出的客观评估, 它是对以往调查 和研究结果的汇总及分析, 因而也就容易发现以往 工作中的不足及空白点, 为今后深入补充调查研究 指明了方向。此次评估结果表明, 苔藓植物中数据 缺乏较多的有细鳞苔科的疮鳞苔属(Cololejeunea), 叶苔科的叶苔属(Jungermannia), 凤尾藓科的凤尾 藓属(Fissidens)及羽苔科的羽苔属(Plagiochila)(何 强和贾渝, 2017); 蕨类植物中数据缺乏较多的有金 星薑科、水龙骨科以及耳蓱属(Polystichum)、蹄盖

表1 中国高等植物红色名录评估结果

Table 1 Species number and percentage of the higher plants in each IUCN red list categories in China

\begin{tabular}{lllllll}
\hline $\begin{array}{l}\text { 等级 } \\
\text { Categories }\end{array}$ & $\begin{array}{l}\text { 苔蘚植物 } \\
\text { Bryophytes }\end{array}$ & $\begin{array}{l}\text { 蕨类植物 } \\
\text { Pteridophytes }\end{array}$ & $\begin{array}{l}\text { 裸子植物 } \\
\text { Gymnosperms }\end{array}$ & $\begin{array}{l}\text { 被子植物 } \\
\text { Angiosperms }\end{array}$ & $\begin{array}{l}\text { 汇总 } \\
\text { Total }\end{array}$ & $\begin{array}{l}\text { 比例 } \\
\text { Percentage (\%) }\end{array}$ \\
\hline 灭绝 EX & 0 & 0 & 0 & 21 & 21 & 0.06 \\
野外灭绝 EW & 0 & 0 & 0 & 9 & 9 & 0.03 \\
地区灭绝 RE & 0 & 0 & 0 & 10 & 10 & 0.03 \\
极危 CR & 16 & 43 & 37 & 518 & 614 & 1.72 \\
濒危 EN & 58 & 68 & 35 & 1,152 & 1,313 & 3.67 \\
易危 VU & 112 & 71 & 76 & 1,693 & 1,952 & 5.45 \\
近危NT & 214 & 66 & 0 & 2,538 & 2,818 & 7.88 \\
无危 LC & 1,900 & 1,124 & 87 & 21,132 & 24,243 & 67.75 \\
数据缺乏 DD & 921 & 872 & 16 & 2,995 & 4,804 & 13.42 \\
合计 Total & 3,221 & 2,244 & 251 & 30,068 & 35,784 & 100 \\
\hline
\end{tabular}




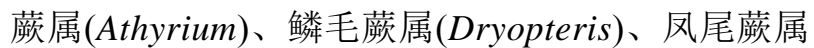
(Pteris)、铁角颜属(Asplenium)等(董仕勇等, 2017); 裸子植物中数据缺乏较多的有刺柏属(Juniperus)、 买麻藤属(Gnetum)、云杉属(Picea) 以及松属(Pinus) 的一些种类(杨永等, 2017); 数据缺乏的被子植物 科属则比较分散, 比较显著的是杜鹃花科、菊科中 的一些中小型属, 小檗科小檗属(Berberis)、卫矛科, 以及禾本科竹类植物等(覃海宁等, 2017b)。上述类 群应该成为今后保护生物学和植物分类学开展野 外居群调查和基于形态性状研究的重点对象。

《中国高等植物红色名录》的编研运用了国际 上广泛认可的IUCN标准, 参考中国植物分类学最 新的研究成果, 并汇集了全国数百位专家的智慧, 是迄今为止评估对象最广、信息最全、参与专家最 多的一次中国植物生存状况评估。它的完成首次从 全国层面摸清了整个中国植物区系的健康状况和 物种濒危的本底状况, 为制订国家及地区性植物多 样性保护规划及策略提供了科学依据, 同时也建立 了物种濒危评估的国家层面平台，包括数据基础、 技术规范和人员队伍, 为今后濒危物种的长期监控 和数据更新奠定了基础(覃海宁和赵莉娜, 2014; 蒋 志刚等, 2016; 藏春金等, 2016)。

\section{4 中国高等植物红色名录后续评估及建议}

红色名录的评估是一个动态而需要长期监测 维护的过程。IUCN (2016) 建议红色名录每隔10年应 予以重新评估, 如果条件允许, 5 年1次更好。一方面, 随着分类学的发展有些物种的分类地位可能出现 变化, 比如物种的归并和科属的拆分, 新的分布点 被发现等; 另一方面, 在国家保护法律法规及保护 工作的有效执行下，部分物种的濒危状况得以改善, 种群得到恢复, 因此, 需要重新评估和调整这些物 种的濒危等级, 准确反映它们的灭绝风险。

自《中国高等植物红色名录》2013年发布以后, 评估小组继续维护该名录, 主要是依据新发表的文 献资料, 对红色名录进行查缺补漏, 包括重新评估 和调整个别物种的濒危等级。尤其是《中国生物物 种名录》(苔藓分册)(贾渝和何思, 2013)和Flora of China蕨类卷 $(\mathrm{Wu}$ et al, 2013b)的出版, 给苔藓植物 和蕨类植物红色名录增添了新的信息, 也使得物种 数量及濒危等级发生了改变。因此, 与 2013 年名录 相比, 本期发表的红色名录无论是种类数量还是等
级均有所变化。

基于红色名录的价值及动态性质, 我们提议建 立一个固定的有效机制以实现中国植物红色名录 的持续更新:

(1)成立红色名录协调机构: 从组织和机制上 保障红色名录的持续更新及推广应用，包括负责制 订红色名录更新计划, 建议政府部门加强对长期红 色名录计划的投入, 将红色名录相关知识纳入到现 有的生物学教学之中, 加强中国红色名录项目与周 边国家以及IUCN全球红色名录项目之间的协调合 作, 等等。协调结构主要由相关政府部门构和学术 机构组成。

(2)成立国家红色名录数据委员会: 委员会直 接受上述协调机构领导, 按照协调机构的要求建立 全国红色名录监测系统, 组织力量开展红色名录信 息更新和实现对名录的修订。委员会成员由学术机 构、NGO、国际组织以及其他的利益团体组成。

致谢: 在《中国高等植物红色名录》的编研过程中, 我们得到环境保护部的资助, 蔡雷博士、薛达元教 授和蒋志刚研究员的指导。全国数十家机构近 300 位专家学者提供物种信息和协助审核名录, IUCN 及其物种生存委员会(SSC)同事Chang Chin Sung 博士、Craig Hilton-Taylor博士、Domitilla C. Raimondo博士、Julie Griffin女士、Kim Hui 博士、Sara Oldfield女士、Sue Mankai博士(已故)、王献溥研究 员 (已故)、解炎博士和周锦超博士等提供帮助。项 目组还得到单位同事王利松、包伯坚、李奕、鲜冬 娅、徐晓婷、张宇澄、陈又生等的协助, 以及《生 物多样性》马克平主编、各位编辑和多位匿名审稿 专家的仔细审校和提出建议, 大大地提高本专刊论 文的质量。在此, 我们对环境保护部及上述各位专 家、老师和同事同行表示衰心的感谢!

\section{参考文献}

Cao T, Zhu RL, Guo SL, Zuo BR, Yu J (2006) A brief report of the first red list of endangered bryophytes in China. Bulletin of Botanical Research, 26, 756-762. (in Chinese with English abstract) [曹同, 朱瑞良, 郭水良, 左本荣, 于晶 (2006) 中国首批濒危苔藓植物红色名录简报. 植物研究, 26, 756-762.]

Cao T, Zhu RL, Tan BC, Guo SL, Gao C, Wu PC, Li XJ (2006) A report of the first national red list of Chinese endangered 
bryophytes. Journal of Hattori Botanical Laboratory, 99, 275-295.

de Grammont PC, Cuarón AD (2006) An evaluation of threatened species categorization systems used on the American continent. Conservation Biology, 20, 14-27.

Dong SY, Zuo ZY, Yan YH, Xiang JY (2017) Red list assenssment of the lycophytes and ferns in China. Biodiversity Science, 25, 765-773. (in Chinese with English abstract) [董 仕勇, 左政裕, 严岳鸿, 向建英 (2017) 中国石松类和硕 类植物的红色名录评估. 生物多样性, 25, 765-773.]

Editorial Committee of China National Biodiversity Conservation Strategy and Action Plan (2011) China National Biodiversity Conservation Strategy and Action Plan (2011-2030). Chinese Environmental Science Press, Beijing. (in Chinese) [中国生物多样性保护战略与行动计划编写组 (2011) 中 国生物多样性保护战略与行动计划(2011-2030). 中国环 境科学出版社, 北京.]

Editorial Committee of China's Strategy for Plant Conservation (2008) China's Strategy for Plant Conservation. Guangdong Science \& Technology Publishing House, Guangzhou. (in Chinese) [中国植物保护战略编撰委员会 (2008) 中国植 物保护战略. 广东科技出版社, 广州.]

Fu LK, Jin JM (1992) China Plant Red Data Book, Vol. 1: Rare and Endangered Plants, English Edition. Science Press, Beijing. [傅立国, 金鉴明 (1991) 中国植物红皮书: 稀有濒 危植物(第一册). 科学出版社, 北京.]

He Q, Jia Y (2017) Assessing the threat status of China's bryophytes. Biodiversity Science, 25, 774-780. (in Chinese with English abstract) [何强, 贾渝 (2017) 中国苔藓植物 濒危等级的评估原则和评估结果. 生物多样性, 25 , 774-780.]

Hong DY, Zhou SL, He XJ, Yuan JH, Zhang YL, Cheng FY (2017) Current status of wild tree peony species with special reference to conservation. Biodiversity Science, 25, 781-793. (in Chinese with English abstract) [洪德元, 周世 良, 何兴金, 袁军辉, 张延龙, 成仿云, 曾秀丽, 王雁, 张 秀新 (2017) 野生牡丹的生存状况和保护. 生物多样性, 25, 781-793.]

Huang JH, Chen JH, Ying JS, Ma KP (2011) Features and distribution patterns of Chinese endemic seed plant species. Journal of Systematics and Evolution, 49, 81-94.

Huang WC, Zhou XY, Ni ZY, Shao L (2015) An assessment of the extinction risk of Calanthe from China based on specimens and field observations. Biodiversity Science, 23, 493-498. (in Chinese with English abstract) [黄卫昌, 周翔 宇, 倪子轶, 邵丽 (2015) 基于标本和分布信息评估中国 虾脊兰属植物的濒危状况. 生物多样性, 23, 493-498.]

IUCN (2001) IUCN Red List Categories and Criteria, Version 3.1. IUCN Species Survival Commission, Gland, Switzerland.

IUCN (2012a) IUCN Red List Categories and Criteria, Version 3.1. Second edition. Gland, Switzerland and Cambridge, UK.
IUCN (2012b) Guidelines for Application of IUCN Red List Criteria at Regional and National Levels, Version 4.0. Gland, Switzerland and Cambridge, UK.

IUCN (2016) Rules of Procedure for IUCN Red List Assessment 2017-2020. Version 3.0. Approved by the IUCN SSC Steering Committee in September 2016. Downloadable from: http://cmsdocs.s3.amazonaws.com/keydocuments/Rules_of Procedure_for_Red_List_2017-2020.pdf.

IUCN Standards and Petitions Subcommittee (2011) Guidelines for Using the IUCN Red List Categories and Criteria, Version 9.0. Prepared by the Standards and Petitions Subcommittee. Downloadable from: http://www.iucnredlist.org/ documents/RedListGuidelines.pdf. (accessed August 2011)

Jia Y, He S (2013) Species Catalogue of China, Vol. 1: Plants (bryophytes). Science Press, Beijing. (in Chinese) [贾渝, 何 思 (2013) 中国生物物种名录: 植物卷 苔藓分册. 科学 出版社, 北京.]

Jiang ZG (2016) Assessing the surviving status of vertebrates in China. Biodiversity Science, 24, 495-499. (in Chinese) [蒋志刚 (2016) 中国脊椎动物生存现状研究. 生物多样 性, 24, 495-499.]

Jiang ZG, Jiang JP, Wang YZ, Zhang E, Zhang YY, Li LL, Xie F, Cai B, Cao L, Zheng GM, Dong L, Zhang ZW, Ding P, Luo ZH, Ding CQ, Ma ZJ, Tang SH, Cao WX, Li CW, Hu HJ, Ma Y, Wu Y, Wang YX, Zhou KY, Liu SY, Chen YY, Li JT, Feng ZJ, Wang Y, Wang B, Li C, Song XL, Cai L, Zang CX, Zeng Y, Meng ZB, Fang HX, Ping XG (2016) Red list of China's Vertebrates. Biodiversity Science, 24, 500-551. (in Chinese and in English) [蒋志刚, 江建平, 王 跃招, 张鹗, 张雁云, 李立立, 谢锋, 蔡波, 曹亮, 郑光 美, 董路, 张正旺, 丁平, 罗振华, 丁长青, 马志军, 汤宋 华, 曹文宣, 李春旺, 胡慧建, 马勇, 吴毅, 王应祥, 周开 亚, 刘少英, 陈跃英, 李家堂, 冯祚建, 王燕, 王斌, 李 成, 宋雪琳, 蔡蕾, 藏春金金, 曾岩, 孟智斌, 方红霞, 平晓 鸽 (2016) 中国脊椎动物红色名录. 生物多样性, 24, 500-551.]

Jiang ZG, Ma KP (2017) The state's will, scientific decision and citizen participation: in memory of the first provincial species red list in China. Biodiversity Science, 25, 794-795. (in Chinese) [蒋志刚, 马克平 (2017) 中国生物多样性保 护的国家意志、科学决策和公众参与：第一份省域物种 红色名录研究. 生物多样性, 25, 794-795.]

Lenzen M, Moran D, Kanemoto K, Foran B, Lobefaro L, Geschke A (2012) International trade drives biodiversity threats in developing nations. Nature, 486, 109-112.

Lucas G, Synge HS (1978) The IUCN Plant Red Data Book. IUCN, Morges, Switzerland.

Mace GM, Collar NJ, Gaston KJ, Hilton-Taylor C, Akçakaya HR, Leader-Williams N, Milner-Gulland EJ, Stuart SN (2008) Quantification of extinction risk: IUCN's system for classifying threatened species. Conservation Biology, 22, 1424-1442.

Mace GM, Lande R (1991) Assessing extinction threats: 
toward a re-evaluation of IUCN threatened species categories. Conservation Biology, 5, 148-157.

Miller RM, Rodríguez JP, Aniskowicz-Fowler T, Bambaradeniya C, Boles R, Eaton MA, Gärdenfors U, Keller V, Molur S, Walker S, Pollock C (2007) National threatened species listing based on IUCN criteria and regional guidelines: current status and future perspectives. Conservation Biology, 21, 684-696.

Ministry of Environmental Protection of the People's Republic of China, Institute of Botany of the Chinese Academy of Sciences (1987) China List of Rare and Endangered Plants, Vol. 1. Science Press, Beijing. (in Chinese) [国家环境保护 局和中国科学院植物研究所 (1987) 中国珍稀濒危保护 植物名录(第一册). 科学出版社, 北京.]

Mittermeier RA, Robles-Gil P, Mittermeier CG (1997) Megadiversity. Earth's Biologically Wealthiest Nations. CEMEX/Agrupaciaon Sierra Madre, Mexico City.

Qin HN, Yang Y, Dong SY, He Q, Jia Y, Zhao LN, Yu SX, Liu HY, Liu B, Yan YH, Xiang JY, Xia NH, Peng H, Li ZY, Zhang ZX, He XJ, Yin LK, Lin YL, Liu QR, Hou YT, Liu Y, Liu QX, Cao W, Li JQ, Chen SL, Jin XH, Gao TG, Chen WL, Ma HY, Geng YY, Jin XF, Chang CY, Jiang H, Cai L, Zang CX, Wu JY, Ye JF, Lai YJ, Liu B, Lin QW, Xue NX (2017a) Threatened Species List of China's Higher Plants. Biodiversity Science, 25, 696-744. (in Chinese and in English) [覃海宁, 杨永, 董仕勇, 何强, 贾渝, 赵莉娜, 于胜 祥, 刘慧圆, 刘博, 严岳鸿, 向建英, 夏念和, 彭华, 李振 宇, 张志翔, 何兴金, 尹林克, 林余霖, 刘全儒, 侯元同, 刘演，刘启新，曹伟，李建强，陈世龙，金效华，高天刚， 陈文俐，马海英，耿玉英，金孝锋，常朝阳，蒋宏，蔡蕾， 蔵春金金, 武建勇, 叶建飞, 赖阳均, 刘冰, 林秦文, 薛纳 新 (2017a) 中国高等植物受威胁物种名录. 生物多样性, 25, 696-744.]

Qin HN, Zhao LN, Yu SX, Liu HY, Liu B, Xia NH, Peng H, Li ZY, Zhang ZX, He XJ, Yin LK, Lin YL, Liu QR, Hou YT, Liu Y, Liu QX, Cao W, Li JQ, Chen SL, Jin XH, Gao TG, Chen WL, Ma HY, Geng YY, Jin XF, Chang CY, Jiang H, Cai L, Zang CX, Wu JY, Ye JF, Lai YJ, Liu B, Lin QW, Xue NX (2017b) Evaluating the endangerment status of China's angiosperms through the red list assessment. Biodiversity Science, 25, 745-757. (in Chinese with English abstract) [覃海宁, 赵莉娜, 于胜祥, 刘慧圆, 刘博, 夏念和, 彭华, 李振宇, 张志翔, 何兴金, 尹林克, 林余霖, 刘全 儒, 侯元同, 刘演, 刘启新, 曹伟, 李建强, 陈世龙, 金效 华, 高天刚, 陈文俐, 马海英, 耿玉英, 金孝锋, 常朝阳, 蒋宏, 蔡蕾, 蔵春金金, 武建勇, 叶建飞, 赖阳均, 刘冰, 林 秦文, 薛纳新 (2017b) 中国被子植物濒危等级的评估. 生物多样性, 25, 745-757.]

Qin HN, Zhao LN (2014) The higher plants of China and the endangered status. In: The Principles of Conservation Biology (eds Jiang ZG, Ma KP), pp. 116-148. Science Press, Beijing. (in Chinese) [覃海宁, 赵莉娜 (2014) 中国高等植 物及其濒危状况. 见: 保护生物学原理 (蒋志刚, 马克平
主编), 116-148页. 科学出版社, 北京.]

Raven PH (2011) Plant conservation in the future: new challenges, new opportunities. Plant Diversity and Resources, 33, 1-9.

Tan LP, Chen ZF (2006) Taxus resources in China. Journal of Northwest Forestry University, 21(6), 113-117. (in Chinese with English abstract) [檀丽萍, 陈振峰 (2006) 中国红豆 杉资源. 西北林学院学报, 21(6), 113-117.]

Tu PF, Jiang Y, Guo YH, Tian YZ, Li XB, Wang XY, Wei J, Chen QL, Aierken M (2015) Developing ecological industry of Cistanches herba for promoting ecological civilization of the western desert region. Modern Chinese Medicine, 17, 297-301. (in Chinese with English abstract) [屠鹏飞, 姜勇, 郭玉海, 田永祯, 李晓波, 王新意, 魏均, 陈庆亮, 艾尔 肯·买提肉孜 (2015) 发展肉获蓉生态产业推进西部荒漠 地区生态文明. 中国现代中药, 17, 297-301.]

Vié JC, Hilton-Taylor C, Pollock C, Ragle J, Smart J, Stuart SN, Tong R (2008) The IUCN Red List: a key conservation tool. In: The 2008 Review of the IUCN Red List of Threatened Species (eds Vié JC, Hilton-Taylor C, Stuart SN). IUCN, Gland, Switzerland.

Vié JC, Hilton-Taylor C, Stuart SN (2009) Wildlife in a Changing World: An Analysis of the 2008 IUCN Red List of Threatened Species. IUCN, Gland, Switzerland.

Wang LS, Jia Y, Zhang XC, Qin HN (2015) Overview of higher plant diversity in China. Biodiversity Science, 23, 217-224. (in Chinese with English abstract) [王利松, 贾渝, 张宪春, 覃海宁 (2015) 中国高等植物多样性. 生物多样 性, 23, 217-224.]

Wang S, Xie Y (2004) China Species Red List, Vol. 1: Red List. Higher Education Press, Beijing. (in Chinese) [汪松, 解炎 (2004) 中国物种红色名录, 第1卷: 红色名录. 高 等教育出版社, 北京.]

Wang YF, Wang Q, Ruan X, Zhang YY (2012) Research status and utilization strategies of rare medicinal plants in Taxus. Scientia Silvae Sinicae, 48(5), 116-125. (in Chinese with English abstract) [王亚飞, 王强, 阮晓, 张莺莺 (2012) 红 豆杉属植物资源的研究现状与开发利用对策. 林业科学, 48(5), 116-125.]

Wei FW, Nie YG, Miao HX, Lu Hao, Hu YB (2014) Advancements of the researches on biodiversity loss mechanisms (in Chinese). Chinese Science Bulletin, 59, 430-437. (in Chinese) [魏辅文, 聂永刚, 苗海霞, 路浩, 胡义波 (2014) 生物多样性丧失机制研究进展. 科学通报, 59, 430-437.]

Wu CY, Raven PH, Hong DY (2013a) Flora of China: Introduction, Vol. 1. Sciences Press, Beijing \& Missouri Botanical Garden, St. Louis.

Wu CY, Raven PH, Hong DY (2013b) Flora of China, Vols. 2-3: Lycopodiaceae through Polypodiaceae. Science Press, Beijing \& Missouri Botanical Garden Press, St. Louis.

Yan YH, Zhang XC, Ma KP (2013) Pteridophytes in China: Diversity and Distribution. Science Press, Beijing. (in 
Chinese) [严岳鸿, 张宪春, 马克平 (2013) 中国蕨类植物 多样性与地理分布. 科学出版社, 北京.]

Yang Y, Liu B, Njenga DM (2017) Red list assessment and conservation status of gymnosperms from China. Biodiversity Science, 25, 758-764. (in Chinese with English abstract) [杨永, 刘冰, Njenga DM (2017) 中国裸子植物物 种濒危和保育现状. 生物多样性, 25, 758-764.]

Zang CX, Cai L, Li JQ, Wu XP, Li XG, Li JS (2016) Preparation of China Biodiversity Red List and its significance for biodiversity conservation of China. Biodiversity Science, 24, 610-614. (in Chinese with English abstract) [蔵春金金, 蔡蕾, 李佳琦, 吴晓莆, 李晓光, 李俊生 (2016)《中国生
物多样性红色名录》的制订及其对生物多样性保护的意 义. 生物多样性, 24, 610-614.]

Zhang LB, Gilbert MG (2015) Comparison of classification of vascular plants of China. Taxon, 64, 17-26.

Zhang XY, Wang YT (2009) Dilemma analysis and conservation strategy. Territory \& Natural Resources Study, 3, 95-96. (in Chinese with English abstract) [张翔宇, 王一涛 (2009) 甘草资源困境分析与保护策略. 国土与自然资源 研究, 3, 95-96.]

\section{附录 Supplementary Material}

\section{附录1 中国高等植物红色名录评估专家名单 (提供数据或审核名录)}

Appendix 1 List of contributors to China Higher Plant Red List (contributed to the text and/or assessment review) http://www.biodiversity-science.net/fileup/PDF/2017-146-1.pdf 
覃海宁和赵莉娜. 中国高等植物濒危状况评估. 生物多样性, 2017, 25 (7): 689-695.

http://www.biodiversity-science.net/CN/10.17520/biods.2017146

附录1 中国高等植物红色名录评估专家名单(提供数据或审核名录)。在此, 我们对所有专家表示诚挚的感谢, 对本名单存在 的一些遗漏表示㒸意。

Appendix 1 List of contributors to China Higher Plant Red List (contributed to the text and/or assessment review)

\begin{tabular}{|c|c|c|}
\hline $\begin{array}{l}\text { 姓名 } \\
\text { Expert name }\end{array}$ & $\begin{array}{l}\text { 单位 } \\
\text { Organization }\end{array}$ & $\begin{array}{l}\text { 科属 } \\
\text { Taxa }\end{array}$ \\
\hline 白学良 BAI Xueliang & 内蒙古大学 & 丛藓科 Pottiaceae, 耳叶苔科 Frullaniaceae 等 \\
\hline 高谦 GAO Qian & 中国科学院沈阳生态研究所 & 叶苔类 Jungermanniaceae \\
\hline 贾渝 JIA Yu & 中国科学院植物研究所 & $\begin{array}{l}\text { 锦蘚科 Sematophyllaceae, 木灵蘚科 Orthotrichaceae, 叶苔科 } \\
\text { Jungermanniaceae, 光萼苔科 Porellaceae }\end{array}$ \\
\hline 裴林英 PEI Linying & 北京林业大学 & 蔓藓科 Meteoriaceae \\
\hline 王庆华 WANG Qinghua & 中国科学院植物研究所 & 木灵藓科 Orthotrichaceae \\
\hline 吴鹏程 WU Pengcheng & 中国科学院植物研究所 & $\begin{array}{l}\text { 平蘚科 Neckeraceae, 扭叶蘚科 Trachypodaceae, 羽藓科 } \\
\text { Thuidiaceae, 细鳞苔科 Lejeuneaceae 等 }\end{array}$ \\
\hline 于宁宁 YU Ningning & 中国科学院植物研究所 & 葓藓科 Pterobryaceae \\
\hline 张满祥 ZHANG Manxiang & 西安植物园 & $\begin{array}{l}\text { 灰蘚科 Hypnaceae, 白齿藓科 Leucodontaceae, 隐蒴藓科 } \\
\text { Cryphaeaceae, 线苔类 Trichocoleaceae }\end{array}$ \\
\hline 曹同 CAO Tong & 上海师范大学 & $\begin{array}{l}\text { 曲尾蘚科 Dicranaceae, 牛毛藓科 Ditrichaceae, 羽苔类 } \\
\text { Plagiochilaceae }\end{array}$ \\
\hline 何强 HE Qiang & 中国科学院植物研究所 & 叉苔科 Metzgeriaceae, 绿片苔科 Aneuraceae 等 \\
\hline 李微 LI Wei & 中国科学院沈阳生态研究所 & 叶苔类 Jungermanniaceae \\
\hline 汪楣芝 WANG Meizhi & 中国科学院植物研究所 & 金发藓科 Polytrichaceae, 地钱类 Marchantiaceae 等 \\
\hline 王幼芳 WANG Youfang & 华东师范大学 & 青蘚科 Brachytheciaceae, 棉藓科 Plagiotheciaceae \\
\hline 吴玉环 WU Yuhuan & 杭州师范大学 & 柳叶蘚科 Amblystegiaceae, 齿蓦苔科 Lophocoleaceae \\
\hline 张力 ZHANG Li & 深圳仙湖植物园 & 溪苔类 Pelliaceae \\
\hline 赵建成 ZHAO Jiancheng & 河北师范大学 & 真藓科 Bryaceae, 提灯藓科 Mniaceae \\
\hline 董仕勇 DONG Shiyong & 中国科学院华南植物园 & $\begin{array}{l}\text { 铁角蕨科 Aspleniaceae, 海南、云南地区硕类 Ferns distributed in } \\
\text { Hainian and Yunnan }\end{array}$ \\
\hline 严岳鸿 YAN Yuehong & $\begin{array}{l}\text { 上海辰山植物园, 中国科学院上海辰山 } \\
\text { 植物科学研究中心 }\end{array}$ & 华中、华南地区葓类 Ferns distributed in South and Central China \\
\hline 邵文 SHAO Wen & 云南大学生态学与地植物学研究所 & 水龙骨科 Polypodiaceae \\
\hline 郭晓思 GUO Xiaosi & 西北农林科技大学生命科学学院 & 石杉科 Huperziaceae \\
\hline 陆树刚 LU Shugang & 云南大学生态学与地植物学研究所 & 西南地区蕨类 Ferns distributed in Southwestern China \\
\hline 王玛丽 WANG Mali & 西北大学生命科学学院 & 蹄盖葓科 Athyriaceae \\
\hline 蒋日红 JIANG Rihong & $\begin{array}{l}\text { 广西壮族自治区/中国科学院广西植物研 } \\
\text { 究所 }\end{array}$ & 广西蕨类 Ferns distributed in Guangxi \\
\hline 卢金梅 LU Jinmei & $\begin{array}{l}\text { 中国科学院昆明植物研究所生物多样性 } \\
\text { 与生物地理学重点实验室 }\end{array}$ & 鳞毛疹科 Dryopteridaceae \\
\hline 刘全儒 LIU Quanru & 北京师范大学生命科学学院 & 北方硕类 Ferns distributed in north China \\
\hline 向建英 XIANG Jianying & $\begin{array}{l}\text { 中国科学院昆明植物研究所生物多样性 } \\
\text { 与生物地理学重点实验室 }\end{array}$ & 鳞毛蕨科 Dryopteridaceae, 云南䕬类 Ferns distributed in Yunnan \\
\hline 陈珍传 CHEN Zhenchuan & 深圳仙湖植物园 & 深圳硕类 Ferns distributed in Shenzhen, Guangdong \\
\hline 李策宏 LI Cehong & 四川省自然资源科学研究院 & 峨眉山菜类 Ferns distributed in Mount Emei \\
\hline 朱圣潮 ZHU Shengchao & 丽水师范专科学校 & 水非科 Isoetaceae \\
\hline 徐成东 XU Chengdong & 云南大学生态学与地植物学研究所 & 云南葓类 Ferns distributed in Yunnan \\
\hline 陈进明 CHEN Jinming & 中国科学院武汉植物园 & 水非科 Isoetaceae \\
\hline 丁炳扬 DING Bingyang & 浙江温州大学生命科学学院 & 浙江硕类 Ferns distributed in Zhejiang \\
\hline 李中阳 LI Zhongyang & 云南大学生态学与地植物学研究所 & 金星蒴科 Thelypteridaceae \\
\hline 宋晓卿 SONG Xiaoqing & 云南大学生态学与地植物学研究所 & 凤尾濒科 Pteridaceae \\
\hline 和兆荣 HE Zhaorong & 云南大学生命科学学院 & 莲座蕨科 Angiopteridaceae, 瓶尔小草科 Ophioglossaceae \\
\hline 何海 HE Hai & 重庆师范大学生命科学学院 & 复叶耳蒴属 Arachniodes \\
\hline
\end{tabular}


覃海宁和赵莉娜. 中国高等植物濒危状况评估. 生物多样性, 2017, 25 (7): 689-695.

http://www.biodiversity-science.net/CN/10.17520/biods.2017146

\begin{tabular}{|c|c|c|}
\hline $\begin{array}{l}\text { 姓名 } \\
\text { Expert name }\end{array}$ & $\begin{array}{l}\text { 单位 } \\
\text { Organization }\end{array}$ & $\begin{array}{l}\text { 科属 } \\
\text { Taxa }\end{array}$ \\
\hline 金水虎 JIN Shuihu & 浙江大学 & 浙江䯾类 Ferns distributed in Zhejiang \\
\hline 刘保东 LIU Baodong & 哈尔滨师范大学生命科学学院 & 东北地区蕨类 Ferns distributed in Northeast China \\
\hline 王发国 WANG Faguo & 中国科学院华南植物园 & 骨碎补科 Davalliaceae, 实蕨科 Bolbitidaceae 等 \\
\hline 杨东梅 YANG Dongmei & 中国科学院华南植物园 & 凤尾鄀科 Pteridaceae \\
\hline 齐新萍 QI Xinping & 中国科学院上海辰山植物科学研究中心 & 水龙骨科瓦韦属 Polypodiaceae (Lepisorus) \\
\hline 詹选怀 ZHAN Xuanhuai & 庐山植物园 & 江西葓类 Ferns distributed in Jiangxi \\
\hline 刘红梅 LIU Hongmei & 仙湖植物园 & 鳞毛蕨科 Dryopteridaceae \\
\hline 张钢民 ZHANG Gangmin & 北京林业大学生物学院 & 中国蕨科 Sinopteridaceae \\
\hline 曾汉元 ZENG Hanyuan & 湖南怀化学院 & 怀化地区蕨类 Ferns distributed in Huaihua, Hunan \\
\hline 杨鲁红 YANG Luhong & 云南大学 & 水龙骨科 Polypodiaceae \\
\hline $\begin{array}{l}\text { 蔡秀珍 CAI Xiuzhen } \\
\text { 胡光万 HU Guangwan }\end{array}$ & $\begin{array}{l}\text { 湖南师范大学生命科学学院 } \\
\text { 中国科学院武汉植物园 }\end{array}$ & $\begin{array}{l}\text { 菖蒲科 Acoraceae, 天南星科 Araceae, 五桠果科 Dilleniaceae } \\
\text { (Tetracera), 竹芋科 Marantaceae }\end{array}$ \\
\hline 曹明 CAO Ming & 广西壮族自治区/中国科学院植物研究所 & 芸香科 Rutaceae (Psilopeganum, Zanthoxylum) \\
\hline 曹瑞 CAO Rui & 内蒙古大学生命科学学院 & 列当科 Orobanchaceae \\
\hline 曹伟 CAO Wei & 中国科学院沈阳应用生态研究所 & 杨柳科 Salicaceae \\
\hline 陈炳辉 CHEN Binghui & 中国科学院华南植物园 & 桑寄生科 Loranthaceae \\
\hline 陈高 CHEN Gao & 中国科学院昆明植物研究所 & 马钱科 Loganiaceae \\
\hline 陈红峰 CHEN Hongfeng & 中国科学院华南植物园 & 伯乐树科 Bretschneideraceae, 马钱科 Loganiaceae \\
\hline 陈家辉 CHEN Jiahui & 中国科学院昆明植物研究所 & 杨柳科 Salicaceae \\
\hline 陈家瑞 CHEN Jiarui & 中国科学院植物研究所 & 柳叶菜科 Onagraceae, 荽麻科 Urticaceae \\
\hline 陈进勇 CHEN Jinyong & 北京市植物园 & 木犀科 Oleaceae (Syringa) \\
\hline 陈丽 CHEN Li & 中国科学院武汉植物园 & 壳斗科 Fagaceae (Castanopsis, Formanodendron) \\
\hline 陈敏 CHEN Min & 中国中医科学院中药研究所 & 葫芦科 Cucurbitaceae (Trichosanthes) \\
\hline 陈绍田 CHEN Shaotian & 中国科学院昆明植物研究所 & $\begin{array}{l}\text { 紫蒇科 Bignoniaceae, 茅亳菜科 Droseraceae, 野牡丹科 } \\
\text { Melastomataceae, 鼠李科 Rhamnaceae } \\
\end{array}$ \\
\hline 陈涛 CHEN Tao & 深圳市仙湖植物园 & 茜草科 Rubiaceae (Pseudopyxis), 安息香科 Styracaceae \\
\hline $\begin{array}{l}\text { 陈文俐 CHEN Wenli } \\
\text { 马海英 MA Haiying }\end{array}$ & $\begin{array}{l}\text { 中国科学院植物研究所 } \\
\text { 云南大学生命科学学院 }\end{array}$ & 禾本科 Poaceae (禾草类) \\
\hline 陈旭波 CHEN Xubo & 浙江丽水学院 & 石竹科 Caryophyllaceae (Stellaria) \\
\hline 陈学林 CHEN Xuelin & 西北师范大学生命科学学院 & 罂粟科 Papaveraceae (Meconopsis) \\
\hline 陈玉峰 CHEN Yufeng & 曲阜师范大学生命科学学院 & 莎草科 Cyperaceae (Fimbristylis, Scirpus) \\
\hline 陈之端 CHEN Zhiduan & 中国科学院植物研究所 & 桦木科 Betulaceae, 胡桃科 Juglandaceae, 葡萄科 Vitaceae \\
\hline $\begin{array}{l}\text { 丛义艳 CONG Yiyan } \\
\text { 刘克明 LIU Keming } \\
\end{array}$ & 湖南师范大学生命科学学院 & 凤仙花科 Balsaminaceae \\
\hline 邓敏 DENG Min & 中国科学院上海辰山植物科学研究中心 & 壳斗科 Fagaceae (Cyclobalanopsis) \\
\hline 邓小芳 DENG Xiaofang & 国家林业局管理干部学院 & 茜草科 Rubiaceae (Mussaenda) \\
\hline 邓云飞 DENG Yunfei & 中国科学院华南植物园 & 爵床科 Acanthaceae \\
\hline 丁雨龙 DING Yulong & 南京林业大学森环学院 & 禾本科 Poaceae (Fargesia, Phyllostachys) \\
\hline 杜凡 DU Fan & 西南林业大学资源学院 & 大风子科 Flacourtiaceae (Idesia, Itoa) \\
\hline 段林东 DUAN Lindong & 湖南邵阳学院城市建设系 & 禾本科 Poaceae (Miscanthus), 茜草科 Rubiaceae (Ophiorrhiza) \\
\hline 凡强 FAN Qiang & 中山大学生命科学学院 & $\begin{array}{l}\text { 海桐花科 Pittosporaceae, 禾本科 Poaceae (Miscanthus), 茜草科 } \\
\text { Rubiaceae (Ophiorrhiza) }\end{array}$ \\
\hline 冯虎元 FENG Huyuan & 兰州大学生命科学学院 & 玄参科 Scrophulariaceae (Pedicularis) \\
\hline 冯缨 FENG Ying & 中国科学院新疆生态与地理研究所 & $\begin{array}{l}\text { 䓤科 Chenopodiaceae (Chenopodium, Corispermum, Dysphania, } \\
\text { Suaeda), 蓄微科 Rosaceae (Potentilla, Prunus, Pyrus, Rosa, Rubus), } \\
\text { 柽柳科 Tamaricaceae (Myricaria, Reaumuria, Tamarix) }\end{array}$ \\
\hline $\begin{array}{l}\text { 傅承新 FU Chengxin } \\
\text { 祁哲晨 QI Zhechen }\end{array}$ & 浙江大学生命科学学院 & 百合科 Liliaceae (Smilax) \\
\hline 高连明 GAO Lianming & 中国科学院昆明植物研究所 & 杜鹃花科 Ericaceae (部分小属) \\
\hline
\end{tabular}


覃海宁和赵莉娜. 中国高等植物濒危状况评估. 生物多样性, 2017, 25 (7): 689-695.

http://www.biodiversity-science.net/CN/10.17520/biods.2017146

\begin{tabular}{|c|c|c|}
\hline $\begin{array}{l}\text { 姓名 } \\
\text { Expert name }\end{array}$ & $\begin{array}{l}\text { 单位 } \\
\text { Organization }\end{array}$ & $\begin{array}{l}\text { 科属 } \\
\text { Taxa }\end{array}$ \\
\hline 高庆波 GAO Qingbo & 中国科学院西北高原生物研究所 & 虎耳草科 Saxifragaceae \\
\hline $\begin{array}{l}\text { 高天刚 GAO Tiangang } \\
\text { 朱世新 ZHU Shixin }\end{array}$ & $\begin{array}{l}\text { 中国科学院植物研究所 } \\
\text { 郑州大学生物工程系 } \\
\end{array}$ & 菊科 Asteraceae \\
\hline 高云东 GAO Yundong & 四川大学生命科学学院 & 石蒜科 Amaryllidaceae (Curculigo, Lycoris) \\
\hline $\begin{array}{l}\text { 耿玉英 GENG Yuying } \\
\text { 金孝锋 JIN Xiaofeng } \\
\text { 张长芹 ZHANG Changqin } \\
\end{array}$ & $\begin{array}{l}\text { 中国科学院植物研究所 } \\
\text { 杭州师范大学生命与环境科学学院中国 } \\
\text { 科学院昆明植物研究所 }\end{array}$ & 杜鹃花科 Ericaceae (Rhododendron etc.) \\
\hline 谷海燕 GU Haiyan & 四川省自然资源科学研究院 & 五福花科 Adoxaceae (Adoxa, Sambucus, Sinadoxa) \\
\hline 郭丽秀 GUO Lixiu & 中国科学院华南植物园 & $\begin{array}{l}\text { 棕桷科 Arecaceae, 五福花科 Adoxaceae (Adoxa, Sambucus, } \\
\text { Sinadoxa) }\end{array}$ \\
\hline 郭延平 GUO Yanping & 北京师范大学生命科学学院 & 菊科 Asteraceae (Achillea) \\
\hline 海鹰 HAI Ying & 新疆师范大学地理科学与旅游学院 & $\begin{array}{l}\text { 白刺科 Nitrariaceae, 蓼科 Polygonaceae (Atraphaxis), 教藜科 } \\
\text { Zygophyllaceae (Peganum, Tetraena, Tribulus, Zygophyllum) }\end{array}$ \\
\hline 韩保财 HAN Baocai & 中国科学院植物研究所 & 豆科 Fabaceae (Astragalus, Bauhinia, Oxytropis, Sophora) \\
\hline 杭悦宇 HANG Yueyu & 江苏省/中国科学院植物研究所 & 薯蓣科 Dioscoreaceae (Dioscorea) \\
\hline 郝刚 HAO Gang & 华南农业大学生命科学学院 & 报春花科 Primulaceae \\
\hline 何顺志 HE Shunzhi & 贵阳中医学院 & $\begin{array}{l}\text { 葫芦科 Cucurbitaceae (Gynostemma), 苦草苔科 Gesneriaceae } \\
\text { (Tengia), 毛莨科 Ranunculaceae (Dichocarpum) }\end{array}$ \\
\hline $\begin{array}{l}\text { 何顺志 HE Shunzhi } \\
\text { 刘演 LIU Yan }\end{array}$ & $\begin{array}{l}\text { 贵阳中医学院 } \\
\text { 广西壮族自治区/中国科学院植物研究所 }\end{array}$ & 百合科 Liliaceae (Aspidistra) \\
\hline $\begin{array}{l}\text { 何顺志 HE Shunzhi } \\
\text { 祁新帅 QI Xinshuai } \\
\end{array}$ & 浙江大学生命科学学院贵阳中医学学院 & 小檗科 Berberidaceae (Dysosma) \\
\hline $\begin{array}{l}\text { 何兴金 HE Xingjin } \\
\text { 胡影禹 HU Haoyu }\end{array}$ & 四川大学生命科学学院 & $\begin{array}{l}\text { 石蒜科 Amaryllidaceae, 百合科 Liliaceae, 薱麻科 Urticaceae } \\
\text { (Pilea) }\end{array}$ \\
\hline 和加卫 HE Jiawei & 云南省农业科学院高山经济植物研究所 & 菩薇科 Rosaceae (Rubus) \\
\hline 侯学良 HOU Xueliang & 厦门大学生命科学学院 & $\begin{array}{l}\text { 番荔枝科 Annonaceae, 大戟科 Euphorbiaceae (Euphorbia), 千屈 } \\
\text { 菜科 Lythraceae (Sonneratia), 红树科 Rhizophoraceae }\end{array}$ \\
\hline $\begin{array}{l}\text { 侯元同 HOU Yuantong } \\
\text { 覃海宁 QIN Haining }\end{array}$ & $\begin{array}{l}\text { 曲阜师范大学生命科学学院 } \\
\text { 中国科学院植物研究所 }\end{array}$ & 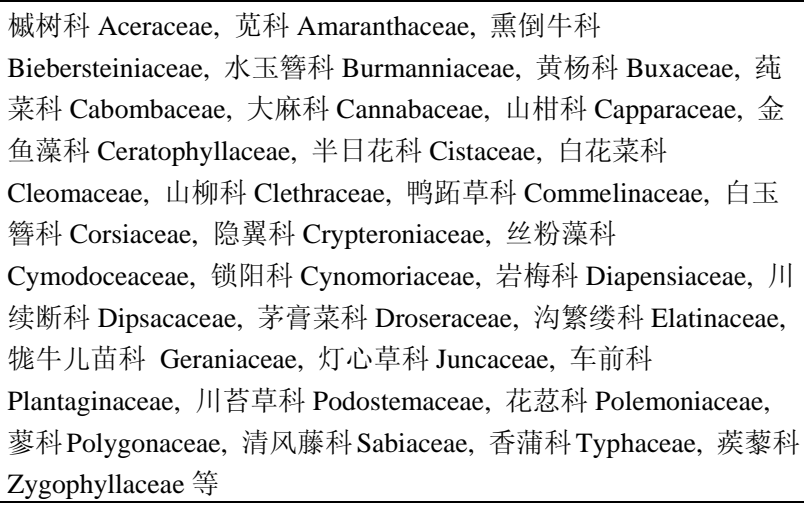 \\
\hline $\begin{array}{l}\text { 侯元同 HOU Yuantong } \\
\text { 刘恩德 LIU Ende } \\
\end{array}$ & $\begin{array}{l}\text { 曲阜师范大学生命科学学院 } \\
\text { 中国科学院昆明植物研究所 }\end{array}$ & $\begin{array}{l}\text { 心翼果科 Cardiopteridacea，杜英科 Elaeocarpaceae，大风子科 } \\
\text { Flacourtiaceae }\end{array}$ \\
\hline 胡光万 HU Guangwan & 中国科学院武汉植物园 & 猖藻科 Lentibulariaceae, 百合科 Liliaceae (Paris) \\
\hline 胡启明 HU Qiming & 中国科学院华南植物园 & 紫金牛科 Myrsinaceae \\
\hline 黄久香 HUANG Jiuxiang & 华南农业大学林学院 & 夹竹桃科 Apocynaceae \\
\hline 黄云峰 HUANG Yunfeng & 广西中医药研究院 & $\begin{array}{l}\text { 兰科 Orchidaceae (Dendrobium, Oxystophyllum, Parapteroceras, } \\
\text { Pleione, Vanda) }\end{array}$ \\
\hline 贾晓光 JIA Xiaoguang & 新疆中药民族药研究所 & 百合科 Liliaceae (Fritillaria) \\
\hline 蒋宏 JIANG Hong & 云南省林科院 & 兰科 Orchidaceae \\
\hline 蒋柱檀 JIANG Zhutan & $\begin{array}{l}\text { 云南省林业厅野生动植物保护管理办公 } \\
\text { 室 }\end{array}$ & 水鳖科 Hydrocharitaceae (Ottelia) \\
\hline $\begin{array}{l}\text { 金孝锋 JIN Xiaofeng } \\
\text { 张长芹 ZHANG Changqin }\end{array}$ & $\begin{array}{l}\text { 杭州师范大学生命与环境科学学院 } \\
\text { 中国科学院昆明植物研究所 }\end{array}$ & 莎草科 Cyperaceae (Carex), 杜鹃花科 Ericaceae (Rhododendron) \\
\hline 金效华 JIN Xiaohua & 中国科学院植物研究所 & 兰科 Orchidaceae \\
\hline
\end{tabular}


覃海宁和赵莉娜. 中国高等植物濒危状况评估. 生物多样性, 2017, 25 (7): 689-695.

http://www.biodiversity-science.net/CN/10.17520/biods.2017146

\begin{tabular}{|c|c|c|}
\hline $\begin{array}{l}\text { 姓名 } \\
\text { Expert name }\end{array}$ & $\begin{array}{l}\text { 单位 } \\
\text { Organization }\end{array}$ & $\begin{array}{l}\text { 科属 } \\
\text { Taxa }\end{array}$ \\
\hline 乐雯培 LE Jipei & 中国科学院昆明植物研究所 & 十字花科 Brassicaceae (Solms-laubachia) \\
\hline 雷立公 LEI Ligong & 中国科学院昆明植物研究所 & 冬青科 Aquifoliaceae, 虎耳草科 Saxifragaceae (Saniculiphyllum) \\
\hline 黎斌 LI Bin & 陕西省西安植物园 & 石竹科 Caryophyllaceae \\
\hline 黎维平 LI Weiping & 湖南师范大学生命科学学院 & 菊科 Asteraceae (Aster, Eurybia) \\
\hline 李波 LI Bo & 江西农业大学农学院 & 马鞭草科 Verbenaceae \\
\hline 李策宏 LI Cehong & 四川省自然资源科学研究院 & 水青树科 Tetracentraceae, 马鞭草科 Verbenaceae (部分) \\
\hline 李家美 LI Jiamei & 河南农业大学生命科学学院 & 苦亘苔科 Gesneriaceae \\
\hline 李建强 LI Jianqiang & 中国科学院武汉植物园 & $\begin{array}{l}\text { 马淣铃科 Aristolochiaceae (Asarum), 景天科 Crassulaceae, 葫芦科 } \\
\text { Cucurbitaceae (Siraitia, Thladiantha) }\end{array}$ \\
\hline 李捷 LI Jie & 中国科学院西双版纳热带植物园 & 樟科 Lauraceae (Litsea) \\
\hline 李进宇 LI Jinyu & 北京林业大学生物科学与技术学院 & 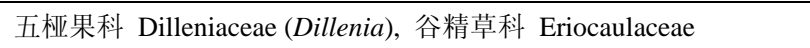 \\
\hline 李琳 LI Lin & 中国科学院华南植物园 & 兰科 Orchidaceae (Tainia) \\
\hline 李巧明 LI Qiaoming & 中国科学院西双版纳热带植物园 & 龙脑香科 Dipterocarpaceae, 兰科 Orchidaceae (Tainia) \\
\hline 李琴琴 LI Qinqin & 四川大学生命科学学院 & 百合科 Liliaceae (Allium) \\
\hline 李嵘 LI Rong & 中国科学院昆明植物研究所 & 五加科 Araliaceae \\
\hline 李睿奇 LI Ruiqi & 中国科学院植物研究所 & 胡桃科 Juglandaceae (Juglans) \\
\hline 李世晋 LI Shijin & 中国科学院华南植物园 & 豆科 Fabaceae (Caesalpinia, Dalbergia, Millettia, Ormosia) \\
\hline 李维林 LI Weilin & 江苏省/中国科学院植物研究所 & 唇形科 Lamiaceae (Mentha), 蓠薇科 Rosaceae (Rubus) \\
\hline 李晓东 LI Xiaodong & 中国科学院武汉植物园 & 玄参科 Scrophulariaceae (Rehmannia, Triaenophora) \\
\hline 李新华 LI Xinhua & 南京农业大学生命科学学院 & 小檗科 Berberidaceae \\
\hline 李新伟 LI Xinwei & 中国科学院武汉植物园 & 猕猴桃科 Actinidiaceae \\
\hline 廖晨阳 LIAO Chenyang & 四川大学生命科学学院 & 伞形科 Apiaceae (Angelica) \\
\hline 廖文波 LIAO Wenbo & 中山大学生命科学学院 & 金缕梅科 Hamamelidaceae \\
\hline 林祁 LIN Qi & 中国科学院植物研究所 & $\begin{array}{l}\text { 八角科 Illiciaceae (Illicium), 五味子科 Schisandraceae, 竹麻科 } \\
\text { Urticaceae }\end{array}$ \\
\hline 林秦文 LIN Qinwen & 中国科学院植物研究所 & 金缕梅科 Hamamelidaceae, 卫矛科 Celastraceae (Microtropis) \\
\hline 刘本胥 LIU Benxi & 中国科学院昆明植物研究所 & 天南星科 Araceae (Remusatia) \\
\hline 刘博 LIU Bo & 中国科学院植物研究所 & $\begin{array}{l}\text { 金粟兰科 Chloranthaceae, 七叶树科 Hippocastanaceae, 桑寄生科 } \\
\text { Loranthaceae, 肉豆蔻科 Myristicaceae, 金莲木科 Ochnaceae, 铁青 } \\
\text { 树科 Olacaceae, 山柚子科 Opiliaceae, 露樂树科 Pandanaceae, 胡椒 } \\
\text { 科 Piperaceae, 檀香科 Santalaceae, 山矾科 Symplocaceae 等 }\end{array}$ \\
\hline 刘恩德 LIU Ende & 中国科学院昆明植物研究所 & 茶荣莫科 Icacinaceae, 楝科 Meliaceae \\
\hline 刘克明 LIU Keming & 湖南师范大学生命科学学院 & 八角枫科 Alangiaceae, 凤仙花科 Balsaminaceae \\
\hline 刘念 LIU Nian & 广东仲恺农业工程学院 & 闭鞘姜科 Costaceae, 姜科 Zingiberaceae \\
\hline 刘启新 LIU Qixin & 江苏省/中国科学院植物研究所 & 伞形科 Apiaceae, 十字花科 Brassicaceae \\
\hline 刘青 LIU Qing & 中国科学院华南植物园 & 禾本科 Poaceae (Sorghum) \\
\hline 刘全儒 LIU Quanru & 北京师范大学生命科学学院 & $\begin{array}{l}\text { 马兒铃科 Aristolochiaceae, 卫矛科 Celastraceae, 旋花科 } \\
\text { Convolvulaceae, 十齿花科 Dipentodontaceae, 川续断科 } \\
\text { Dipsacaceae, 大戟科 Euphorbiaceae, 豆科 Fabaceae (部分), 败酱科 } \\
\text { Valerianaceae 等 }\end{array}$ \\
\hline 刘爽 LIU Shuang & 四川大学生命科学学院 & 半形科 Apiaceae (Ligusticum) \\
\hline $\begin{array}{l}\text { 刘腾聙 LIU Tengjing } \\
\text { 黎维平 LI Weiping }\end{array}$ & $\begin{array}{l}\text { 兰州大学生命科学学院 } \\
\text { 湖南师范大学生命科学学院 } \\
\end{array}$ & 菊科 Asteraceae (Ligularia) \\
\hline 刘演 LIU Yan & 广西壮族自治区/中国科学院植物研究所 & 秋海棠科 Begoniaceae, 千屈菜科 Lythraceae \\
\hline 刘艳 LIU Yan & 重庆市林业科学研究院 & 茜草科 Rubiaceae (Morinda) \\
\hline 罗世孝 LUO Shixiao & 中国科学院华南植物园 & $\begin{array}{l}\text { 大戟科 Euphorbiaceae (Glochidion, Phyllanthus)，马鞭草科 } \\
\text { Verbenaceae (Clerodendrum) }\end{array}$ \\
\hline 罗艳 LUO Yan & 中国海洋大学生命科学学院 & $\begin{array}{l}\text { 忍冬科 Caprifoliaceae (Lonicera), 毛茛科 Ranunculaceae (Coptis, } \\
\text { Aconitum) }\end{array}$ \\
\hline 马海英 MA Haiying & 云南大学生命科学学院 & 番杏科 Aizoaceae, 金虎尾科 Malpighiaceae, 禾本科 Poaceae (部 \\
\hline
\end{tabular}


覃海宁和赵莉娜. 中国高等植物濒危状况评估. 生物多样性, 2017, 25 (7): 689-695.

http://www.biodiversity-science.net/CN/10.17520/biods.2017146

\begin{tabular}{|c|c|c|}
\hline $\begin{array}{l}\text { 姓名 } \\
\text { Expert name }\end{array}$ & $\begin{array}{l}\text { 单位 } \\
\text { Organization }\end{array}$ & $\begin{array}{l}\text { 科属 } \\
\text { Taxa }\end{array}$ \\
\hline & & 分), 远志科 Polygalaceae \\
\hline 牟风娟 MOU Fengjuan & 西南林业大学资源学院 & 芸香科 Rutaceae (Clausena, Glycosmis, Murraya) \\
\hline 沐先运 MU Xianyun & 北京林业大学生物科学与技术学院 & 卫矛科 Celastraceae (Bhesa, Celastrus) \\
\hline 潘伯荣 PAN Borong & 中国科学院新疆生态与地理研究所 & 菶科 Polygonaceae (Calligonum) \\
\hline 彭华 PENG Hua & 中国科学院昆明植物研究所 & $\begin{array}{l}\text { 桃叶珊瑚科 Aucubaceae, 旋花科 Convolvulaceae (Ipomoea, } \\
\text { Merremia), 山荣英科 Cornaceae, 青荚叶科 Helwingiaceae, 锦葵科 } \\
\text { Malvaceae, 紫茉莉科 Nyctaginaceae, 西番莲科 Passifloraceae, 山龙 } \\
\text { 眼科 Proteaceae, 三白草科 Saururaceae, 省沽油科 Staphyleaceae, } \\
\text { 椴树科 Tiliaceae 等 }\end{array}$ \\
\hline 齐耀东 QI Yaodong & 中国医学科学院药用植物研究所 & 瑞香科 Thymelaeaceae \\
\hline 钱关泽 QIAN Guanze & 聊城大学生命科学学院 & 萻微科 Rosaceae \\
\hline 秦新生 QIN Xinsheng & 华南农业大学林学院 & 萝藦科 Asclepiadaceae \\
\hline 任保青 REN Baoqing & 太原市太山植物园筹建处 & $\begin{array}{l}\text { 华木科 Betulaceae (Alnus, Betula, Carpinus, Corylus, Ostrya, } \\
\text { Ostryopsis) }\end{array}$ \\
\hline $\begin{array}{l}\text { 任毅 REN Yi } \\
\text { 赵亮 ZHAO Liang }\end{array}$ & 陕西师范大学生命科学学院 & $\begin{array}{l}\text { 星叶草科 Circaeasteraceae, 毛茛科 Ranunculaceae (Adonis, } \\
\text { Anemone, Coptis, Halerpestes, Kingdonia, Metanemone, Naravelia, } \\
\text { Paraquilegia) }\end{array}$ \\
\hline 萨仁 SHA Ren & 中国科学院植物研究所 & 榆科 Ulmaceae \\
\hline 石祥刚 SHI Xianggang & 中山大学生命科学学院 & 杜英科 Elaeocarpaceae (Elaeocarpus) \\
\hline 宋柱秋 SONG Zhuqiu & 广西自然博物馆 & 豆科 Fabaceae (Hylodesmum) \\
\hline 孙国峰 SUN Guofeng & 中国科学院植物研究所 & 百合科 Liliaceae (Lilium) \\
\hline 孙航 SUN Hang & 中国科学院昆明植物研究所 & $\begin{array}{l}\text { 豆科 Fabaceae (Acacia, Adenanthera, Albizia, Calliandra, Entada, } \\
\text { Hedysarum), 茜草科 Rubiaceae (Nostolachma) }\end{array}$ \\
\hline 孙坤 SUN Kun & 西北师范大学生命科学学院 & 胡颓子科 Elaeagnaceae (Elaeagnus, Hippophae) \\
\hline $\begin{array}{l}\text { 孙苗 SUN Miao } \\
\text { 孙坤 SUN Kun }\end{array}$ & $\begin{array}{l}\text { 中国科学院植物研究所 } \\
\text { 西北师范大学生命科学学院 }\end{array}$ & 胡颓子科 Elaeagnaceae (Elaeagnus) \\
\hline 孙庆文 SUN Qinwen & 贵阳中医学院 & $\begin{array}{l}\text { 五膜草科 Pentaphragmataceae, 桔梗科 Campanulaceae, 菊科 } \\
\text { Asteraceae (Bidens, Xanthium) }\end{array}$ \\
\hline 谭敦炎 TAN Dunyan & 新疆农业大学草业与环境科学学院 & 百合科 Liliaceae (Tulipa) \\
\hline 谭进波 TAN Jinbo & 四川大学生命科学学院 & 菊科 Asteraceae (Cremanthodium) \\
\hline 唐光大 TANG Guangda & 华南农业大学林学院 & 兰科 Orchidaceae (Liparis) \\
\hline 童毅华 TONG Yihua & 中国科学院华南植物园 & 无患子科 Sapindaceae \\
\hline 王长宝 WANG Changbao & 四川大学生命科学学院 & 企形科 Apiaceae (Bupleurum, Carlesia) \\
\hline 王辰 WANG Chen & 中国国家地理博物杂志社 & $\begin{array}{l}\text { 丝粉藻科 Cymodoceaceae, 波喜荡科 Posidoniaceae, 眼子菜科 } \\
\text { Potamogetonaceae, 大花草科 Rafflesiaceae 等 }\end{array}$ \\
\hline 王国勋 WANG Guoxun & 中国科学院植物研究所 & 蓄薇科 Rosaceae (Sorbus) \\
\hline 王恒昌 WANG Hengchang & 中国科学院武汉植物园 & 防已科 Menispermaceae (Stephania) \\
\hline 王军 WANG Jun & 中国科学院华南植物园 & $\begin{array}{l}\text { 紫金牛科 Myrsinaceae (Aegiceras, Ardisia, Embelia, Maesa, } \\
\text { Myrsine) }\end{array}$ \\
\hline 王康 WANG Kang & 北京市植物园 & 五福花科 Adoxaceae (Viburnum), 木犀科 Oleaceae (Fraxinus) \\
\hline 王强 WANG Qiang & 中国科学院植物研究所 & 唇形科 Lamiaceae (Microtoena) \\
\hline 王戌梅 WANG Shumei & 西安交通大学医学院 & 苶科 Polygonaceae (Rheum) \\
\hline 王伟 WANG Wei & 中国科学院植物研究所 & 木通科 Lardizabalaceae, 防已科 Menispermaceae \\
\hline 王贤荣 WANG Xianrong & 南京林业大学森环学院 & 蓄薇科 Rosaceae (Cerasus, Prunus) \\
\hline 王亚玲 WANG Yaling & 陕西省西安植物园 & 木兰科 Magnoliaceae (Yulania) \\
\hline 王一峰 WANG Yifeng & 西北师范大学生命科学学院 & 菊科 Asteraceae (Himalaiella, Saussurea) \\
\hline 王英伟 WANG Yingwei & 中国科学院植物研究所 & 罂粟科 Papaveraceae \\
\hline 王志新 WANG Zhixin & 四川大学生命科学学院 & 半形科 Apiaceae (Pimpinella) \\
\hline 韦发南 WEI Fanan & 广西壮族自治区/中国科学院植物研究所 & 樟科 Lauraceae \\
\hline 吴宝成 WU Baocheng & 江苏省/中国科学院植物研究所 & 石蒜科 Amaryllidaceae (Lycoris) \\
\hline
\end{tabular}


覃海宁和赵莉娜. 中国高等植物濒危状况评估. 生物多样性, 2017, 25 (7): 689-695.

http://www.biodiversity-science.net/CN/10.17520/biods.2017146

\begin{tabular}{|c|c|c|}
\hline $\begin{array}{l}\text { 姓名 } \\
\text { Expert name }\end{array}$ & $\begin{array}{l}\text { 单位 } \\
\text { Organization }\end{array}$ & $\begin{array}{l}\text { 科属 } \\
\text { Taxa }\end{array}$ \\
\hline 武建勇 WU Jianyong & 环保部南京环境科学研究所 & 小檗科 Berberidaceae (Mahonia) \\
\hline 夏念和 XIA Nianhe & 中国科学院华南植物园 & $\begin{array}{l}\text { 金粟兰科 Chloranthaceae, Lowiaceae, 桑寄生科 Loranthaceae, 木 } \\
\text { 兰科 Magnoliaceae, 肉豆冦科 Myristicaceae, 金莲木科 } \\
\text { Ochnaceae, 铁青树科 Olacaceae, 露兜树科 Pandanaceae, 胡椒科 } \\
\text { Piperaceae, 禾本科 Poaceae (竹子), 檀香科 Santalaceae, 无患子科 } \\
\text { Sapindaceae 等 }\end{array}$ \\
\hline 向春雷 XIANG Chunlei & 中国科学院昆明植物研究所 & 唇形科 Lamiaceae \\
\hline 邢福武 XING Fuwu & 中国科学院华南植物园 & $\begin{array}{l}\text { 香茜科 Carlemanniaceae, 红树科 Rhizophoraceae, 茜草科 } \\
\text { Rubiaceae }\end{array}$ \\
\hline $\begin{array}{l}\text { 邢福武 XING Fuwu } \\
\text { 间丽春 YAN Lichun }\end{array}$ & $\begin{array}{l}\text { 中国科学院华南植物园 } \\
\text { 中国科学院西双版纳热带植物园 }\end{array}$ & $\begin{array}{l}\text { 茜草科 Rubiaceae (Antirhea, Canthium, Clarkella, Damnacanthus, } \\
\text { Leptodermis) }\end{array}$ \\
\hline $\begin{array}{l}\text { 邢福武 XING Fuwu } \\
\text { 周劲松 ZHOU Jinsong }\end{array}$ & $\begin{array}{l}\text { 中国科学院华南植物园 } \\
\text { 广州中医药大学中药学院药用植物学教 } \\
\text { 研室 }\end{array}$ & 堇菜科 Violaceae \\
\hline 徐朗然 XU Langran & 西北农林科技大学生命科学学院 & $\begin{array}{l}\text { 豆科 Fabaceae (Astragalus, Caragana, Glycyrrhiza, Lathyrus, } \\
\text { Phyllolobium) }\end{array}$ \\
\hline 徐颂军 XU Songjun & 华南师范大学资环学院 & 梧桐科 Sterculiaceae \\
\hline 许炳强 XU Bingqiang & 中国科学院华南植物园 & 木犀科 Oleaceae \\
\hline 许为斌 XU Weibin & 广西壮族自治区/中国科学院植物研究所 & $\begin{array}{l}\text { 藤黄科 Clusiaceae, 交让木科 Daphniphyllaceae, 柿树科 } \\
\text { Ebenaceae, 樟科 Lauraceae (Machilus, Neolitsea), 千屈菜科 } \\
\text { Lythraceae, 山榄科 Sapotaceae }\end{array}$ \\
\hline 薛春迎 XUE Chunying & 中国科学院昆明植物研究所 & 龙胆科 Gentianaceae (Swertia) \\
\hline 间丽春 YAN Lichun & 中国科学院西双版纳热带植物园 & 香茜科 Carlemanniaceae, 茜草科 Rubiaceae \\
\hline $\begin{array}{l}\text { 间丽春 YAN Lichun } \\
\text { 邢福武 XING Fuwu }\end{array}$ & $\begin{array}{l}\text { 中国科学院西双版纳热带植物园 } \\
\text { 中国科学院华南植物园 }\end{array}$ & 茜草科 Rubiaceae \\
\hline 间双喜 YAN Shuangxi & 河南农业大学林学院 & 卫矛科 Celastraceae (Euonymus) \\
\hline 阳文静 YANG Wenjing & 中国科学院植物研究所 & 毛莨科 Ranunculaceae (Clematis, Thalictrum) \\
\hline 杨大荣 YANG Darong & 中国科学院西双版纳热带植物园 & 桑科 Moraceae \\
\hline $\begin{array}{l}\text { 杨福生 YANG Fusheng } \\
\text { 李攀 LI Pan }\end{array}$ & $\begin{array}{l}\text { 中国科学院植物研究所 } \\
\text { 浙江大学生命科学学院 }\end{array}$ & 玄参科 Scrophulariaceae (Scrophularia) \\
\hline 杨青松 YANG Qingsong & 云南民族大学化学与生物技术学院 & 壳斗科 Fagaceae (Cyclobalanopsis, Quercus) \\
\hline 杨世雄 YANG Shixiong & 中国科学院昆明植物研究所 & 山茶科 Theaceae \\
\hline 杨拓 YANG Tuo & 中国科学院植物研究所 & 清风藤科 Sabiaceae (Meliosma) \\
\hline 叶华谷 YE Huagu & 中国科学院华南植物园 & 马钱科 Loganiaceae (Mitreola) \\
\hline 叶建飞 YE Jianfei & 中国科学院植物研究所 & 半形科 Apiaceae (Pternopetalum) \\
\hline 尹林克 YIN Linke & 中国科学院新疆生态与地理研究所 & $\begin{array}{l}\text { 紫草科 Boraginaceae, 藜科 Chenopodiaceae, 白花丹科 } \\
\text { Plumbaginaceae, 柽柳科 Tamaricaceae }\end{array}$ \\
\hline 余岩 YU Yan & 四川大学生命科学学院 & 企形科 Apiaceae (Heracleum) \\
\hline $\begin{array}{l}\text { 郁文涁 YU Wenbin } \\
\text { 杨福生 YANG Fusheng }\end{array}$ & $\begin{array}{l}\text { 中国科学院西双版纳热带植物园 } \\
\text { 中国科学院植物研究所 }\end{array}$ & 玄参科 Scrophulariaceae (Pedicularis) \\
\hline 喻勋林 YU Xunlin & 中南林业科技大学林学院 & 泽江科 Alismataceae, 玄参科 Scrophulariaceae (Pedicularis) \\
\hline 袁琼 YUAN Qiong & 中国科学院华南植物园 & 毛莨科 Ranunculaceae \\
\hline 袁书杰 YUAN Shujie & 四川大学生命科学学院 & 大戟科 Euphorbiaceae (Hancea, Mallotus) \\
\hline 藏德奎 ZANG Dekui & 山东农业大学林学院 & 木犀科 Oleaceae (Osmanthus) \\
\hline $\begin{array}{l}\text { 翟伟 ZHAI Wei } \\
\text { 闵平 YAN Ping } \\
\end{array}$ & $\begin{array}{l}\text { 新疆农业大学草业与环境科学与学院 } \\
\text { 新疆石河子大学生命科学学院 }\end{array}$ & 豆科 Fabaceae (Astragalus, Phyllolobium) \\
\hline 张彩飞 ZHANG Caifei & 中国科学院植物研究所 & 菊科 Asteraceae (Pertya) \\
\hline 张长芹 ZHANG Changqin & 中国科学院昆明植物研究所 & $\begin{array}{l}\text { 杜鹃花科 Ericaceae (Rhododendron), 百合科 Liliaceae (Tupistra), } \\
\text { 蓝果树科 Nyssaceae }\end{array}$ \\
\hline $\begin{array}{l}\text { 张长芹 ZHANG Changqin } \\
\text { 耿玉英 GENG Yuying }\end{array}$ & $\begin{array}{l}\text { 中国科学院昆明植物研究所 } \\
\text { 中国科学院植物研究所 }\end{array}$ & 杜鹃花科 Ericaceae (Rhododendron) \\
\hline 张发起 ZHANG Faqi & 中国科学院西北高原生物所 & 龙胆科 Gentianaceae \\
\hline
\end{tabular}


覃海宁和赵莉娜. 中国高等植物濒危状况评估. 生物多样性, 2017, 25 (7): 689-695.

http://www.biodiversity-science.net/CN/10.17520/biods.2017146

\begin{tabular}{|c|c|c|}
\hline $\begin{array}{l}\text { 姓名 } \\
\text { Expert name }\end{array}$ & $\begin{array}{l}\text { 单位 } \\
\text { Organization }\end{array}$ & $\begin{array}{l}\text { 科属 } \\
\text { Taxa } \\
\end{array}$ \\
\hline 张光富 ZHANG Guangfu & 南京师范大学生命科学学院 & 木兰科 Magnoliaceae (Yulania) \\
\hline 张建文 ZHANG Jianwen & 中国科学院昆明植物研究所 & 菊科 Asteraceae (Melanoseris, Soroseris, Syncalathium) \\
\hline 张金政 ZHANG Jinzheng & 中国科学院植物研究所 & 感尾科 Iridaceae (Crocus, Iris) \\
\hline 张景博 ZHANG Jingbo & 中国科学院植物研究所 & 莎草科 Cyperaceae (Carex) \\
\hline 张玲 ZHANG Ling & 中国科学院西双版纳热带植物园 & 蒟蒻薯科 Taccaceae (Schizocapsa, Tacca) \\
\hline 张树仁 ZHANG Shuren & 中国科学院植物研究所 & 莎草科 Cyperaceae \\
\hline 张燕君 ZHANG Yanjun & 中国科学院武汉植物园 & 小檗科 Berberidaceae (Epimedium) \\
\hline 张雨曲 ZHANG Yuqu & 陕西师范大学生命科学学院 & 禾本科 Poaceae (Fargesia) \\
\hline 张玉霄 ZHANG Yuxiao & 中国科学院昆明植物研究所 & $\begin{array}{l}\text { 禾本科 Poaceae (Acidosasa, Ampelocalamus, Chimonocalamus, } \\
\text { Ferrocalamus, Gaoligongshania, Indocalamus, Indosasa, Pseudosasa, } \\
\text { Sasa) }\end{array}$ \\
\hline 张毓 ZHANG Yu & 北京市植物园 & 兰科 Orchidaceae (Cypripedium) \\
\hline 张志翔 ZHANG Zhixiang & 北京林业大学生物科学与技术学院 & $\begin{array}{l}\text { 五桠果科 Dilleniaceae, 蓄薇科 Rosaceae (Fragaria), 椴树科 } \\
\text { Tiliaceae (Tilia) }\end{array}$ \\
\hline 张志耘 ZHANG Zhiyun & 中国科学院植物研究所 & $\begin{array}{l}\text { 蛇菰科 Balanophoraceae, 葫芦科 Cucurbitaceae, 金缕梅科 } \\
\text { Hamamelidaceae, 列当科 Orobanchaceae, 茄科 Solanaceae }\end{array}$ \\
\hline 赵丽华 ZHAO Lihua & 四川大学生命科学学院 & 百合科 Liliaceae (Heteropolygonatum, Polygonatum) \\
\hline 赵利清 ZHAO Liqing & 内蒙古大学生命科学学院 & 禾本科 Poaceae \\
\hline 赵以民 ZHAO Yimin & 广西药用植物园 & 百合科 Liliaceae (Aletris) \\
\hline 郑朝汉 ZHENG Chaohan & 中国科学院华南植物园 & 禾本科 Poaceae (竹子类) \\
\hline 郑卉 ZHENG Hui & 四川大学生命科学学院 & 蓄薇科 Rosaceae (Potentilla) \\
\hline 郑永利 ZHENG Yongli & 中国科学院华南植物园 & 苦菅苔科 Gesneriaceae (部分) \\
\hline 周劲松 ZHOU Jinsong & $\begin{array}{l}\text { 广州中医药大学中药学院药用植物学教 } \\
\text { 研室 }\end{array}$ & 堇菜科 Violaceae \\
\hline 周静 ZHOU Jing & 中国科学院昆明植物研究所 & 半形科 Apiaceae (Peucedanum) \\
\hline 周庆源 ZHOU Qingyuan & 中国科学院植物研究所 & 浮萍科 Lemnaceae, 芸香科 Rutaceae (Phellodendron) \\
\hline 周世良 ZHOU Shiliang & 中国科学院植物研究所 & $\begin{array}{l}\text { 五加科 Araliaceae (Panax), 腊梅科 Calycanthaceae, 唇形科 } \\
\text { Lamiaceae (Mosla), 䓎药科 Paeoniaceae }\end{array}$ \\
\hline 周伟 ZHOU Wei & 中国科学院华南植物园 & 壳斗科 Fagaceae (Lithocarpus) \\
\hline 周忠泽 ZHOU Zhongze & 安徽师范大学生命科学学院 & 蓼科 Polygonaceae (Fagopyrum, Polygonum) \\
\hline 朱长山 ZHU Changshan & 河南农业大学生命科学学院 & $\begin{array}{l}\text { 五福花科 Adoxaceae (Sambucus), 忍冬科 Caprifoliaceae } \\
\text { (Heptacodium, Leycesteria, Symphoricarpos, Triosteum), 锦带花科 } \\
\text { Diervillaceae, 北极花科 Linnaeaceae }\end{array}$ \\
\hline 朱格麟 ZHU Gelin & 西北师范大学生命科学学院 & 紫草科 Boraginaceae, 藜科 Chenopodiaceae \\
\hline 朱世新 ZHU Shixin & 郑州大学生物工程系 & 菊科 Asteraceae (Anaphalis, Lactuca) \\
\hline 朱相云 ZHU Xiangyun & 中国科学院植物研究所 & 豆科 Fabaceae (Oxytropis) \\
\hline 朱昱苹 ZHU Yuping & 南京大学生命科学学院 & 豆科 Fabaceae (Archidendron, Oxytropis), 㫋节花科 Stachyuraceae \\
\hline 庄雪影 ZHUANG Xueying & 华南农业大学林学院 & $\begin{array}{l}\text { 樟科 Lauraceae (Alseodaphne, Machilus, Phoebe), 桃金娘科 } \\
\text { Myrtaceae }\end{array}$ \\
\hline
\end{tabular}

